Open Access

\title{
Students' feedback beliefs and anxiety in online foreign language oral tasks
}

Sidney Martin ${ }^{1^{*}}$ (D) and Ibis M. Alvarez Valdivia ${ }^{2}$

\footnotetext{
* Correspondence: smartinmot@uoc.edu 1Universitat Oberta de Catalunya, Rambla del Poblenou, 156, 08018 Barcelona, Spain

Full list of author information is available at the end of the article
}

\begin{abstract}
Research about the interrelation between anxiety and corrective feedback has mostly been conducted in face-to-face environments. The present study examines the relationship between students showing anxiety when speaking a FL and feedback as a potential anxiety inhibitor in an online oral synchronous communication task. Two questionnaires, the Foreign Language Anxiety Scale (FLAS) and the Corrective Feedback Belief Scale (CFBS), were administered to 50 students from the School of Languages in an online learning environment. T-test analysis showed a significant difference between the learners' preferences in two methods of CF. Recast and Metalinguistic feedback were better rated by the students who reported higher levels of anxiety in oral communication classes. Additionally, the High-level anxiety group rated teacher feedback as more effective than the other sources of feedback when compared to the Low-level anxiety group. These results indicate the need to take into account individual differences in terms of anxiety foreign language learning and students' beliefs about CF in order to help them achieve their learning goals in an interactive online environment.
\end{abstract}

Keywords: Feedback, Foreign language anxiety, e-Learning, Interactive learning environment

\section{Introduction}

Anxiety is an element that hinders the learning of a foreign language (FL), especially in speaking tasks (Zhang \& Rahimi 2014). However, feedback can help reduce anxiety levels, and in turn, increase students' confidence. Most of the research about the relationship between anxiety and corrective feedback has mostly been conducted in faceto-face environments. Several studies on these two factors have been performed in a classroom context (Abedi, Mahadavi, \& Hassaskhah 2015; Renko 2012), but very little has been has examined them in e-learning. The present study examines the relationship between students showing anxiety when speaking a FL and feedback as a potential anxiety inhibitor in e-learning. In particular, this study explores how anxiety in learning a FL in a virtual environment, specifically in speaking tasks, relates to the beliefs that students have about corrective feedback. More specifically, our study proposes the use of Skype in a speaking class in which a student interacts with a teacher.

\section{Literature review}

\section{Defining e-learning from a constructivist perspective}

Although the definition of e-learning is elusive, Koohang, Riley, Smith, and Schreurs (2009) define it as education delivered by means of electronic media. However, we 
adopt the definition of Tavangarian, Leypold, Nölting, Röser, and Voigt (2004), who provide a more precise definition of what e-learning is and which is couched in constructivist terms:

We will call e-Learning all forms of electronic supported learning and teaching, which are procedural in character and aim to effect the construction of knowledge with reference to individual experience, practice and knowledge of the learner. Information and communication systems, whether networked or not, serve as specific media (specific in the sense elaborated previously) to implement the learning process (p.274).

It is our belief that such definition portrays briefly and concisely what e-learning consists of and includes two key elements in the concept, education and information technology (IT). Also, one must take into account the instructional design of e-learning, which currently relies on constructivism as the most adequate learning model, thus promoting the use of prior knowledge in order to build new knowledge (Koohang 2009).

Murphy (1997) provides a description of constructivism learning theory, based on a thorough review of literature. Among the traits included in the description, there is particularly one that has direct bearing on our study, which is that of taking into account the learners' previous attitudes and beliefs in the process of knowledge construction. Our results on beliefs can then help online instructors to provide the feedback students need to perform better within the constructivist framework.

Koohang (2009) puts forward a constructivist model for e-learning in which three key elements play an important role for learning to occur: learning activities design; learning assessment and the instructor's roles. The design of learning activities should aim at promoting cooperation, scaffolding, dealing with the real-world as well as social negotiation. Secondly, learning assessment is carried out in three levels including instructor, peer and self-assessment. Finally, the instructor's role is essentially that of a guide, coach and feedback provider. All these three key elements provide the very foundations of a constructivist e-learning environment, which according to Lin (2015) fosters greater interaction opportunities in L2 learning.

In sum, constructivists emphasize the design of learning environment rather than instructional sequences (Jonassen 1994), where the principles for active learning, such as creating a learning environment for real life learning, social interaction and an experiential learning environment (Huang 2002a, 2002b), are of vital importance in order to favour learning in authentic learning tasks (Herrington \& Reeves 2003).

Studies of the effect of technology-enhanced instruction on achievement and studies of student attitudes regarding learning with technology have also increasingly been reported. For instance, Yu, She, and Lee (2010) found that low-achieving students could benefit from web-instructional methods. Also, Ward, Moule, and Lockyer (2009) found that the students in their study were not interested in using social networks as a learning tool. The results of these studies will help us better understand students' needs so as to reduce their level of anxiety and make them feel more comfortable when speaking a FL in virtual environments. In principle, these environments facilitate interaction between students and student-teacher; increase motivation; improve self-concept and mastery of basic skills; and enhance more student-centred learning and engagement in the learning process as well as more active processing, resulting in higher-order 
thinking skills and better recall. Students also appear to gain confidence by directing their own learning (i.e. Coverdale-Jones 2000; De los Arcos, Coleman, \& Hampel, 2009; Stepp-Greany, 2002). More specifically, various studies have demonstrated the importance of using Interface Delivery Systems, thus facilitating interactions in real time between teachers and students as in Synchronous Audiographic Conferencing systems (SAC systems) and Skype (Hassan Das, Hassan, Bisdikian, \& Soldani, 2005; Roseberry, Hirsh-Pasek, \& Golinkoff 2014). Some studies have observed that the use of technology fosters autonomous learning and decreases students' anxiety towards the use of technology as a helping tool for their learning process (Huang, 2002a). Additionally, the use of technology is even beneficial for the assessment of language learning tasks (i.e. Hopkins, 2010).

\section{Foreign language anxiety}

Anxiety is an emotional and individual characteristic which has an important role in learning a FL, also known as Foreign Language Anxiety (FLA). FLA is specific to a particular situation and is associated with learning a foreign language or with having to communicate using it (Ellis, 2006). Such anxiety involves a sense of tension and also negative emotional reaction (MacIntyre 1999, cited in Dörnyei, 2005). Krashen (1982) sees a negative relationship between anxiety and feedback, specifically corrective feedback (CF). Feedback may adversely affect the emotional areas of the student, which, in turn, can negatively affect learning, especially in speaking tasks. If students do not understand the reason why there is feedback in the classroom, feedback could be considered as something threatening. However, if both the teacher and the student understand the role of feedback in learning, levels of anxiety decrease and thus learning is unlikely to be harmed (Horwtiz et al. 1986).

In general, it is considered that anxiety is a subjective feeling of tension, nervousness and worry, which is associated with the activation of the automatic nervous system (Zheng, 2008), the source of which, in the case of learning, would be a combination of all of these factors. In particular, Zhang and Rahimi (2014) identified six sources of anxiety: a) personal problems and / or interpersonal; b) the interaction between teacher and student; c) procedures in the classroom; d) the assessment of language; e) what the teacher thinks about learning; f) what students think about learning. Our study focuses on the assessment of language as one of the sources of anxiety, contextualized in a constructivist approach where formative rather than summative assessment is encouraged and $\mathrm{CF}$, in tandem with its emotional impact on students, plays a critical role in order to scaffold one's learning.

Also, one should consider that students' L1 can influence the degree of difficulty when learning another language (Zhanming, 2014). The fact that the literature on levels of anxiety in learning a FL show different results may be due to many variables such as the students' L1 and target language (Abedi, Mahadavi, \& Hassaskhah, 2015; Baralt \& Gurzynski-Weiss 2011; Martínez 2013; Renko 2012; Sheen 2008).

\section{Corrective feedback}

Feedback is key in e-learning and formative assessment, as it seeks to improve student learning through the information the teacher provides, which allows students both to 
reactivate and consolidate prior knowledge as well as to focus on important aspects of what they are learning (Boud \& Molloy 2013; Shute 2007). Carless (2007) states that feedback should be turned into feedforward and in order to do so, feedback should promote learning by having students engage with it and act upon it.

There is ample literature on feedback mechanisms in both traditional and virtual contexts (Ion, Silva, \& Cano 2013). However, there are few studies that relate these mechanisms to the levels of anxiety that students can present when carrying out speaking tasks in e-learning environments. For instance, McNeil (2014) found that FLA in an asynchronous computer-mediated learning environment is low. However, FLA peaked in specific contexts such as in peer-assessment, grammar or pronunciation tasks, to name a few, which are not that different from face-to-face contexts as potential sources of FLA. Last but not least, it is vital that researchers who want to carry out a more pedagogically-based research should take the perception of the student into account (Hopkins 2010).

In this sense, Abedi et al. (2015) recommend considering the levels of anxiety when giving feedback and suggest investigating possible relationships between these factors, especially in relation to speaking tasks, which are perceived as the toughest tasks by most students of FL. The present study is focused on corrective feedback (CF) provided to students when carrying out speaking tasks in an interactive online environment. It is assumed that $\mathrm{CF}$ is a response to errors in the interventions made by a student (Ellis 2006). Seemingly, the impact of CF in learning is not always positive since in some cases it can increase student anxiety (Krashen 1982). Teachers should also be careful with the amount of feedback that is provided. That is, too little or too much would be detrimental to the student. Interestingly, related to the two factors that we are investigating in our study, CF and anxiety, recast is only effective for students who show a low degree of anxiety (Lee 2016; Sheen 2008).

In line with this concern, Zhang and Rahimi (2014) examined the beliefs of students on CF after being informed about the purpose, significance and types of CF. The CF strategies used in the study are as follows: Clarification request (the teacher asks students to repeat what they said); Repetition (the teacher emphasizes the student's grammatical error by changing his/her tone of voice); Explicit correction (the teacher gives the correct form to the student with a grammatical explanation); Elicitation (the teacher asks the student to correct and complete the sentence); Metalinguistic feedback (the teacher gives a hint or a clue without specifically pointing out the mistake); Recast (the teacher repeats the student's utterance in the correct form without pointing out the student's error); and No corrective feedback (the teacher does not give CF on the student's errors). The results indicated that regardless of their anxiety level both groups had similar beliefs about CF and strongly favoured receiving frequent CF in English oral communication classes when they were made aware of the purpose, significance, and types of CF. Similarly, Abedi et al. (2015) present six CF strategies: explicit correction; recast; clarification request; meta-linguistic clues; elicitation and the repetition of the mistake. Regardless of their level of anxiety, the students in their study expressed similar beliefs regarding CF.

Renko (2012) observed that, of all the corrective feedback strategies investigated in their research, explicit correction and metalinguistic feedback create the least amount of anxiety in the learners. In this sense, Lyster and Ranta (1997) argued that 
metalinguistic feedback entails high-quality feedback and fosters uptake. Lochtman (2002) believes that the less-effective strategies are recast and correction, which is in agreement with the results observed by Surakka (2007).

In this respect, Ozmen and Aydın (2015) showed that although most student teachers held a constructivist belief in defining teaching, their oral corrective feedback strategies varied in terms of correcting errors that relate to language proficiency, language components and task type. Also, in this study, the participants highlighted the importance of the learners' reactions toward feedback.

\section{The feedback sources: teacher feedback, peer feedback, and self-assessment}

One last aspect worth considering is the source of CF. The most common feedback is feedback provided by a teacher (sometimes referred to as instructor). Gielen, Tops, Dochy, Onhema, and Smeets (2010) highlighted that teacher feedback is more complex than peer feedback and usually is interpreted by the learner as more reliable and effective. "Teachers also bring expertise in judgment from experience on similar tasks, giving them insight into various ways to solve the assignment and in the difficulties previous learners encountered" (p. 144).

In relation to the effects of teacher feedback on learning, a number of studies compare teacher feedback to peer feedback. In general, they highlight the benefits of both types of feedback, though students prefer teacher feedback, considering it more reliable (Ertmer et al. 2007; Van den Boom, Paas, \& Van Merriënboer 2007).

Kavaliauskiene and Anusiene (2012) investigate students' attitudes towards the source of $\mathrm{CF}$ and found that peer-feedback is only effective where there is a friendly and cooperative environment. In addition, based on their results, they strongly recommend not interrupting students while they are speaking but instead teachers should wait until the end of the task in order not to undermine the student's self-esteem. Furthermore, the fact that students who are being assessed feel more communicative pressure when their interlocutor is someone with higher power and knowledge, such as a teacher, may also increase their anxiety (Ahmadi \& Sadeghi 2016). Self-assessment is considered a viable alternative to formal second language assessment for placement and criterion-referenced interpretations, although variation in self-assessment validity coefficients suggests potential difficulty in accurate interpretation (Ross 1998). Learners can use this feedback to evaluate their approach to language learning. Nevertheless, the conclusions of several self-assessment studies are somewhat contradictory (Blanche \& Merino 1989) since teachers and students perceived the effectiveness of self-assessment differently, depending on their teaching/learning contexts (Butler \& Lee 2010).

Zhang and Rahimi (2014) investigated three sources in a face-to-face environment: teacher, peer and self-correction. Their results show that students value teachers' CF the most, followed by student peer-feedback, and self-correction was the least favoured. Abedi et al. (2015), in a face-to-face study, coincides with Zhang and Rahimi (2014) in that teacher CF is the most favoured. Rollinson (2005) found in face-to-face environments that peer-feedback is less authoritarian and more supportive but students perceive it as less useful. Along the same lines, Renko (2012) showed that students with high levels of anxiety preferred less CF from teachers. On the other hand, Tseng and 
Tsai (2007) concluded that reinforcing feedback that provides a positive feeling or recognition of the work and suggestive feedback provided by peers are most useful for subsequent learning. Although this research generally reports that the value of peer feedback is seen as being equivalent to instructor feedback in terms of reliability and value, students still report feeling insecure when they are evaluated only by a peer and do not receive the expert knowledge attributed to the instructor (Ertmer et al. 2007).

Taking these findings together, some differential impacts of feedback sources on developing skills are stated in favour of the teacher.

\section{The present study}

Research has shown that CF and FLA are related in foreign language learning (Krashen 1982; Horwitz, Horwitz \& Cope 1986; Sheen 2008; Renko 2012; Zhang \& Rahimi 2014) in both face-to-face and asynchronous online contexts (McNeil 2014). However, little has been investigated about the relationship between FLA and synchronous computer mediated language learning, as in online speaking tasks.

The major purpose of our study is to explore the relationship between anxiety in learning a FL and the beliefs students have about the feedback they receive from their teachers while carrying out synchronous online speaking tasks. Within the scope of this main aim, an answer to the following question has been sought: In virtual teaching and learning environments, are students' beliefs on their teachers' feedback related to students' level of anxiety when learning a FL? Also, how do students perceive different types of CF and does such perception vary as a function of their level of anxiety?

\section{Method}

\section{Context of the study}

The participants were enrolled in an Intermediate English language course (B1.1) at the School of Languages at a Spanish university, which has been fully online since its foundation (more information about its pedagogic and assessment model can be found on the university's website: http://www.uoc.edu/portal/en/centre-modern-languages/). Here communication skills play an important role during both written and oral language as it is used in a context of communicative learning, using asynchronous audio and video recordings on LANGblog and synchronous interactions between students via Skype-Tandem. It should be stressed that only student-student interaction is offered in the speaking tasks for B1.1. This restriction justifies the decision to collect their views on feedback from the consultant in a hypothetical situation where teachers and students do interact synchronously.

\section{Participants}

A total of 50 students enrolled in an Intermediate English Language course, which is the equivalent of B1.1 level according to the Common European Framework, participated in the study. More than half (66\%) were women. Also, two thirds of the participants were older than $25(66 \%)$. Catalan is the mother tongue of almost two thirds (64\%). Slightly over half of the participants (58\%) were first-time online students. Other interesting facts about the participants are that the majority (76\%) started 
learning English during their compulsory schooling years (7-15 years old) and very few have lived or worked in an English-speaking country (96\%). In addition, only a minority has any contact with English speakers (12\%). Finally, slightly over a third of the participants use English at work (36\%).

\section{Instruments}

In order to collect the data, two questionnaires have been adapted, through which more demographic information has been collected (gender, age, mother tongue, language learning experience with online experience with courses, other issues related to language learning). The original instruments were translated from English into both Spanish and Catalan by the first author, who is a native speaker of English, Catalan and Spanish. A series of back translation procedures were employed to verify the accuracy of the translations, with the aid of Spanish and Catalan native speakers (two university professors with e-learning experience). Any discrepancies were discussed as well as the questionnaires revised and again back-translated in the few instances where necessary.

a Foreign Language Classroom Anxiety Scale (FLCAS) (adapted from Horwtiz, Horwitz, \& Cope 1986) was used as a measure of the students' specific anxiety reaction towards the learning of a foreign language. This scale consists of 33 items worded as a 5-point Likert-type scale, ranging from "strongly agree" (5 points) to "strongly disagree". It was designed to assess the degree to which learners feel anxious about learning during English class, including the dimensions of Comfortableness in using English inside and outside the classroom, which is made up of items reflecting students' ease when using English, either at school or with a native speaker outside (sample item: "I never feel quite sure of myself when I am speaking in my foreign language class"); Communication Apprehension, which contains items that indicate anxiety, shyness and bodily reactions towards speaking in the foreign language (sample item: "I get nervous and confused when I am speaking in my language class"); Speech anxiety, which contains a group of items indicating circumstances and components of the foreign language learning context. These, as a result of cognitive appraisal, are understood as ego-threatening and result in anxiety response. Items 29,15 and 4 are related to the students' fear of not understanding their teacher (sample item: "It frightens me when I don't understand what the teacher is saying in the foreign language"); items 7 and 23 are related to the students' fear of doing worse than their classmates (sample item: "I keep thinking that the other students are better at languages than I am"); Fear of failing the Class (items 16, 25, 30) (sample item: "Even if I am well prepared for language class, I feel anxious about it"); and Negative attitudes toward Learning English (items 6 and 17) (sample item: "During language class, I find myself thinking about things that have nothing to do with the course"). These dimensions loaded on four separate dimensions in the original study by Aida (1994). In the current Spanish sample, the items pertaining to Communication Apprehension, Speech anxiety, and Negative attitudes toward Learning English were best described by a single Anxiety factor, whose alpha for internal consistency for the 23 items was .944. This factor, explaining $46.7 \%$ of the variance, greatly accounts for the Foreign Language Anxiety 
construct. The alpha for the 3-item Comfortableness with the Foreign Language factor was .59. Inasmuch as the internal consistency of this factor was marginal, we included these data for heuristic value only given their substantive importance. The results should be interpreted with caution.

b Corrective Feedback Belief Scale (CFBS) (adapted from Fukuda 2004). This instrument collects the beliefs students have on the feedback received when speaking in a foreign language. From the first to the end of the sixth category, there were 22 items which were aimed at the exploration of students' judgments about the giving and receiving of spoken error correction, frequency of giving and receiving spoken error correction, time of spoken error correction, types of errors which need to be corrected, types of spoken error correction and sources for providing spoken error correction, and specific CF methods. Each of the above mentioned items in the questionnaire form had been designed based on a 5-point-Likert-scale ranking in "strongly agree, agree, neutral, disagree, strongly disagree" or "always, usually, sometimes, occasionally, never" also, "very effective, effective, neutral, ineffective, very ineffective". The alpha reliabilities for CFBS and FLCAS in the present study were .731, indicating acceptable internal consistency for the instrument (Devellis 2001). In addition, since only parts of the questionnaire were used in the present study, the reliability index of the four sections was estimated as follows: time of spoken error correction $(\alpha=0.754)$, types of spoken errors that need to be corrected $(\alpha=0.880)$, sources for providing spoken error correction $(\alpha=0.749)$, and specific CF methods $(\alpha=0.59)$.

\section{Procedure}

The two questionnaires, merged into a single document divided into two parts, were distributed online (Google Surveys) to reduce costs and enable participants to fill in the online questionnaire by means of an invitation containing a link to it. The invitation containing the link briefly explained the research proposal. After reading the message, respondents had to decide whether to participate or not. If they decided to do so by clicking on the link, they were sent to the questionnaire which had an introduction in which the aim of the survey was again explained with a respectful and understandable language, while making it clear that it was a voluntary survey and that their data would remain confidential. After answering some demographic questions, the participants moved on to the FLCAS and then to the CFBS.

Students were contacted via their class tutors who published a message on their Notice boards in their online classrooms after having received their coordinator's approval. After 2 weeks approximately a reminder was published following the aforementioned procedure. Students had the possibility of completing the survey in Catalan or in Spanish so two sets of surveys were available online. 41 students out of 50 chose the Catalan version.

In order to identify anxious and non-anxious participants in the whole group $(n=50)$, a cluster analysis was performed. More specifically, in this study, we applied the two-step clustering and hierarchical clustering with squared Euclidian distances. Hierarchical Cluster Analysis is the primary statistical method for finding relatively homogeneous clusters of cases based on measured characteristics. It 
starts with each case as a separate cluster, and then combines the clusters sequentially, reducing the number of clusters at each step until only one cluster remains (Aldenderfer \& Blashfield 1984). The respondents were clustered based on the variable Anxiety $(M=74.38, S D=16.71)$, yielding two clearly distinct groups. Finally, 23 participants or $46 \%$ were grouped into the first cluster group, characterized by high scores $(M=79, S D=15.64)$, and 27 or $54 \%$ into the second cluster group $C 2$, characterized by lower scores $(M=53, S D=18.03)$. Analyses were made using the Statistical Package for Social Sciences 20.0 (version 20.0 for Windows, SPSS Inc., Chicago, IL, USA).

\section{Results}

Our aim was to explore the relationship between anxiety in learning a FL and the beliefs students have about the feedback they receive from their teachers while carrying out synchronous online speaking tasks. The differences were sought with regard to the necessity and frequency of CF; methods of CF, timing, types of errors, and choice of correctors. In the following sections, participants' responses are reported with regard to their beliefs about $\mathrm{CF}$ in oral synchronous communication task.

\section{Necessity and frequency of the feedback}

With regards to the responses of the high- and low-anxiety groups to the necessity of error correction ("I want to receive corrective feedback (e.g., provide a hint for me to self-correct, tell me that I have made an error, or correct my error) when I make mistakes"), $88 \%$ of the students in the high- and $100 \%$ of the students in the low-anxiety groups responded "strongly agree" or "agree". Furthermore, both groups agree that they take into account CF in future tasks. Regardless of their level of anxiety, both groups were in favour of receiving CF frequently. As illustrated in Table 1, there was no statistically significant difference between the two groups.

The results clearly indicate that the students in both groups, regardless of their level of anxiety in oral communication classes, were in favour of receiving CF.

\section{Methods of feedback}

As far as methods of CF are concerned, the students in both groups rated Explicit correction as the most effective method, followed by Metalinguistic feedback, Repetition by the teacher, Clarification, Elicitation and Recast. No corrective feedback was the least favoured method by the two groups.

Table 1 High-/low-anxiety group responses to the Necessity and Frequency of CF

\begin{tabular}{|c|c|c|c|c|c|c|c|}
\hline \multirow[b]{2}{*}{ Items } & \multicolumn{2}{|c|}{$\begin{array}{l}\text { Low anxiety } \\
(n=27)\end{array}$} & \multicolumn{2}{|c|}{$\begin{array}{l}\text { High anxiety } \\
(n=23)\end{array}$} & \multirow[b]{2}{*}{$t$-value } & \multirow[b]{2}{*}{$p$} & \multirow[b]{2}{*}{$95 \% \mathrm{Cl}$} \\
\hline & Mean & $S D$ & Mean & $D$ & & & \\
\hline Necessity of error correction (item 1) & 4.26 & .70 & 4.40 & .13 & -1.095 & .279 & {$[-.55, .26]$} \\
\hline $\begin{array}{l}\text { Take into account corrective feedback } \\
\text { in future tasks (item 19) }\end{array}$ & 4.11 & .75 & 4.47 & .64 & .765 & .061 & {$[-.80, .09]$} \\
\hline Frequency of CB (item 2) & 3.36 & .87 & 3.16 & .82 & .827 & .132 & {$[-.64, .43]$} \\
\hline
\end{tabular}


However, as we show in Table 2, T-test analysis showed a significant difference between the learners' preferences only in two methods of CF: Recast and Metalinguistic feedback, which were better rated by students who reported higher levels of anxiety in oral communication classes.

\section{Types of errors to correct}

Responses to types of errors to correct have also been analysed, showing that both High- and Low-level anxiety groups agree that Serious errors was a priority (LA: M = $3.45, S D=.61$, and HA: $M=3.67, S D=.62$ ), followed by Frequent errors (LA: $M=3.25$, $S D=.91$, and HA: $\mathrm{M}=3.60, \mathrm{SD}=.63$ ), Individual errors $(\mathrm{LA}: \mathrm{M}=3.37, S D=.88$, and HA: $\mathrm{M}=3.53, \mathrm{SD}=.74$ ), Minor errors (LA: $\mathrm{M}=2.90, S D=.85$, and $\mathrm{HA}: \mathrm{M}=3.00, S D$ $=.68$ ) and Infrequent errors (LA: $\mathrm{M}=2.75, S D=1.07$, and HA: $\mathrm{M}=3.00, S D=.79$ ). However, there were not any statistically significant differences between the preferences in the two groups of participants about the types of errors to correct.

As for the timing of Feedback, both high and low anxiety groups consider that CF is most effective after finishing speaking (LA:M $=4.15, S D=.91$, and $\mathrm{HA}: \mathrm{M}=4.07, S D$ $=.58)$, CF after the activity ( $\mathrm{LA}: \mathrm{M}=3.90, S D=1.7$, and $\mathrm{HA}: \mathrm{M}=3.50, S D=1.22)$, then Immediate CF (LA: $\mathrm{M}=3.40, S D=1.04$, , and $\mathrm{HA}: \mathrm{M}=3.33, \mathrm{SD}=1.12$ ), and finally $\mathrm{CF}$ at the conclusion of class ( $\mathrm{LA}: \mathrm{M}=3.30, S D=1.29$., and $\mathrm{HA}: \mathrm{M}=2.67, S D=1.28$ ). In addition, the High-level anxiety group always scores higher than the Low anxiety group with only one exception, which is Immediate CF. However, there were not any statistically significant differences between the two groups.

\section{Source of feedback}

Table 3 shows the responses of both groups when it comes to the source of the correction. Regardless of their level of anxiety, Teachers were the most valued, followed by Myself and Classmates, which is the least valued by the leaners. T-test analysis showed a significant difference between the preferences related with the Teacher as source of CF. That is, the Low-level anxiety group values Teacher feedback as more effective than the other sources of feedback when compared to the High-level anxiety group.

Table $\mathbf{2}$ Low/high Anxiety group responses to Methods of CF

\begin{tabular}{|c|c|c|c|c|c|c|c|}
\hline \multirow[b]{2}{*}{ Methods of CF } & \multicolumn{2}{|c|}{$\begin{array}{l}\text { Low anxiety } \\
(n=27)\end{array}$} & \multicolumn{2}{|c|}{$\begin{array}{l}\text { High anxiety } \\
(n=23)\end{array}$} & \multirow[b]{2}{*}{$t$-value } & \multirow[b]{2}{*}{$p$} & \multirow[b]{2}{*}{$95 \% \mathrm{Cl}$} \\
\hline & $M$ & $S . D$ & $\bar{M}$ & $S . D$ & & & \\
\hline Explicit correction (item 6) & 4.12 & 1.05 & 4.27 & 1.12 & -1.249 & .154 & {$[-.95,1.05]$} \\
\hline Metalinguistic feedback (item 9) & 3.69 & .79 & 4.07 & .961 & -1.359 & $.043^{*}$ & {$[-.83, .88]$} \\
\hline Repetition by the teacher (item 5) & 3.68 & 1.1 & 3.83 & 1.19 & -.375 & .258 & {$[-.64, .65]$} \\
\hline Clarification request (item 4) & 3.49 & .95 & 3.87 & 1.25 & .546 & .417 & {$[.45, .44]$} \\
\hline Elicitation (item 7) & 3.35 & .92 & 3.67 & 1.18 & -1.106 & .226 & {$[-.89, .92]$} \\
\hline Recast (item 10) & 3.20 & 1.19 & 3.37 & .74 & -.715 & $.032^{*}$ & {$[-.91, .43]$} \\
\hline No corrective feedback(item 8) & 1.85 & .87 & 2.03 & .66 & -.784 & .176 & {$[.65, .63]$} \\
\hline
\end{tabular}


Table 3 Low/high Anxiety group responses to Source of CF

\begin{tabular}{|c|c|c|c|c|c|c|c|}
\hline \multirow[b]{2}{*}{ Source of Feedback } & \multicolumn{2}{|c|}{$\begin{array}{l}\text { Low anxiety } \\
(n=27)\end{array}$} & \multicolumn{2}{|c|}{$\begin{array}{l}\text { High anxiety } \\
(n=23)\end{array}$} & \multirow[b]{2}{*}{$t$-value } & \multirow[b]{2}{*}{$p$} & \multirow[b]{2}{*}{$95 \% \mathrm{Cl}$} \\
\hline & $\overline{M e a n}$ & $S D$ & $\overline{M e a n}$ & SD & & & \\
\hline Teachers (item 17) & 4.70 & .48 & 4.53 & .62 & 1.01 & $.048^{*}$ & {$[-.56, .59]$} \\
\hline Myself (item 18) & 3.60 & 1.06 & 3.80 & 1.24 & -.612 & .837 & {$[-.85, .45]$} \\
\hline Classmates (item 16) & 3.15 & .95 & 3.13 & .973 & .058 & .715 & {$[-.16, .49]$} \\
\hline
\end{tabular}

Finally, no significant differences have been observed between the sociodemographic variables and the preference for a specific type of feedback or the timing of the CF and neither for any of the types of errors nor source of feedback.

\section{Discussion}

This study aims at answering the following questions: In virtual teaching and learning environments, are students' beliefs on their teachers' feedback related to students' level of anxiety when learning a FL? Also, how do students perceive different types of CF and does such perception vary as a function of their level of anxiety? In this sense, our study yielded some interesting results, which will now be discussed.

First, both High- and Low-anxiety groups strongly support provision of CF in oral tasks, which is in line with what Zhang and Rahimi (2014) found in their study. Respondents, regardless of their anxiety level, were very interested in using CF in order to improve their future tasks, which is encouraging for teachers to see since feedback to be considered as such needs to be engaging (Carless 2007). Tseng and Tsai (2007) concluded that reinforcing feedback that provides a positive feeling or recognition of the work and suggestive feedback provided by peers are most useful for subsequent learning. Clearly, CF is in intimate relation with a student's emotional make-up and needs to go hand in hand for positive outcomes (Ozmen \& Aydın 2015).

Interestingly, respondents in both groups seem not to like too much CF. These results are not in keeping with the ones in Zhang and Rahimi (2014), whose respondents chose Usually and Immediate CF as their most preferred answers while our respondents chose Sometimes. It is also worth mentioning that the High-level anxiety group in our study consistently scores higher than the Low-level anxiety group in Immediate CF. Such pattern may be due to the fact that Immediate CF may interrupt the natural flow of speech and that it may also undermine both the speaker's confidence and increase anxiety, especially in the high-level anxiety group. The results agree with some of the findings in Martínez (2013) where nearly two-thirds of his participants reported resent and worry when their teacher immediately corrected them and that almost half of the participants hated making oral mistakes, thus undermining their confidence.

As far as responses to types of errors to correct are concerned, both High- and Lowlevel anxiety groups agree that Serious errors are a priority, which is also observed in Zhang and Rahimi (2014) and Abedi et al. (2015). It is fair to add that Zhang and Rahimi (2014) also think that Serious problems are a source of great anxiety, confusion and disappointment in communication, thus leading often times to communicative breakdown. We may partially agree with such explanations since our participants have 
registered for a communicative course in nature, which is well-grounded on constructivism (active learning in real-life situations), thus encouraging students to interact by means of tools such as Skype. Any communicative breakdown in such a context can prove problematic for the speakers.

Second, concerning appraisal of different types of CF, the students in both groups rated explicit correction as the most effective strategy, which confirms that most of the teachers' oral CF had positive impacts on the students' affective variables, specifically lowering their anxiety about speaking English (Lee 2016; Renko 2012; Zhang \& Rahimi 2014).

More interestingly, the pattern seems to be also true across learning environments, since the participants of our study are from an online environment. In particular, our study showed that Recast and Metalinguistic feedback were better rated by the students who reported higher levels of anxiety in oral communication classes, which is critical information for tutors when delivering feedback. Partially contradicting results can be found in Abedi et al. (2015), who found elicitation, implicit correction and recast as the most effective methods irrespective of the anxiety level of the participants. In fact, the students' online learning environment, in which active learning and interaction inspired by constructivism occurs, leads students to view specific CF methods as more effective such as Metalinguistic feedback, which entails high-quality feedback and fosters uptake (Lyster \& Ranta 1997).

Finally, our results also reveal that all the students prefer feedback coming from the teacher. When it comes to the source of the correction, both anxiety groups scored Teachers the highest followed by Myself and then Classmates, which is the least valued. By and large, our results are in line with other researchers who also found teachers as the most preferred source for CF, considering it as more reliable (Ertmer et al. 2007; Van den Boom et al. 2007). These results may contradict Baralt and Gurzynski-Weiss (2011) and Ahmadi and Sadeghi (2016) where teachers may be a cause for greater anxiety when they are also the interlocutors in a task, especially due to differentials in power relationships. Therefore, teachers seem to have a critical role when delivering CF in both face-to-face and online environments since according to our study and Zhang and Rahimi (2014), students consider teachers as their prime source of knowledge and expertise. In addition, one must consider a possible influence from the learning environment when we see that self-correction is in second position in our study while it is last in Zhang and Rahimi (2014) since self-evaluation is encouraged in e-learning (Hopkins 2010). Furthermore, Butler and Lee (2010) stated that teachers and students perceived the effectiveness of self-assessment differently depending on their teaching/ learning contexts.

In general terms, the two research questions have been answered by providing evidence. We have evidence that confirms the fact that in virtual teaching and learning environments students' beliefs on their teachers' feedback is related to students' level of anxiety when learning a FL, which is in line with similar findings in face-to-face learning environments. Furthermore, students' perception of different types of CF does vary as a function of their level of anxiety also in line with face-to-face learning environments. However, interestingly, students in an online environment have shown slightly different preferences in types of CF, showing that the learning environment may have a significant effect on CF preference. 
This result is relevant for teachers since they become critical in motivating their students in order to foster positive feelings towards learning a FL. Thus, creating an online learning environment for real life learning, social interaction and an experiential learning environment (free-anxiety environment) is very important in order to favour learning in authentic learning tasks (Herrington \& Reeves 2003; Huang 2002a, 2002b). In this context, corrective feedback could be more engaging, and thus can reduce levels of anxiety in FL learning.

While the results here have validity with respect to our environment and population, they were, nonetheless, limited by a number of factors. For instance, the fact that it is about the participants' beliefs on CF in a hypothetical situation of which students have no experience and solely rely on their face-to-face experience in speaking tasks may be one of them. Perhaps, the same study with participants who have experienced online synchronous speaking tasks with a teacher would yield different results. Secondly, the size of the population is relatively small. Also, we cannot be positive about the reasons for choosing specific answers without further looking into the matter in more depth by way of either a new survey asking participants about the reasons for choosing their answers or even an interview, which would either way allow us to collect qualitative data so as to shed some more light onto our present results. Last but not least, future research would need to include both more and face-to-face participants in the study, using the same research tools for comparison purposes. Baralt and Gurzynski-Weiss (2011) failed to find significant differences in state anxiety between face-to-face and computer-mediated communication among students of Intermediate Spanish. However, as the same authors have suggested, there are new aspects that are in need of further study, such as the interaction between the place where the research is carried out and levels of anxiety as well as task type and levels of anxiety. Indeed, such information will be considered in our future research.

Competing interests

The authors declared no potential conflicts of interest with respect to the research, authorship, and/or publication of this article.

\title{
Publisher's Note
}

Springer Nature remains neutral with regard to jurisdictional claims in published maps and institutional affiliations.

\author{
Author details \\ ${ }^{1}$ Universitat Oberta de Catalunya, Rambla del Poblenou, 156, 08018 Barcelona, Spain. ${ }^{2}$ Universitat Autònoma de \\ Barcelona, Barcelona, Spain.
}

Received: 9 March 2017 Accepted: 24 April 2017

Published online: 05 June 2017

References

Abedi, Z., Mahadavi, A., \& Hassaskhah, J. (2015). Iranian EFL learners' preferred oral corrective feedback: high anxious learners vs. low anxious learners. International Journal of Research Studies in Language Learning, 5(2), 75-86.

Ahmadi, A., \& Sadeghi, E. (2016). Assessing English language learner's oral performance: a comparison of monologue, interview and group oral test. Language Assessment Quarterly, 13(4), 341-358.

Aida, Y. (1994). Examination of Horwitz, Horwitz, and Cope's construct of foreign language anxiety: the case of student of Japanese. The Modern Language Journal, 78, 155-168.

Aldenderfer, M. S., \& Blashfield, R. K. (1984). Cluster analysis. Beverly Hills: Sage Publications.

Baralt, M., \& Gurzynski-Weiss, L. (2011). Comparing learners' state anxiety during task-based interaction in computermediated and face-to-face communication. Language Teaching Research, 15(2), 201-229.

Blanche, P., \& Merino, B. J. (1989). Self-Assessment of foreign-language skills: implications for teachers and researchers. Language Learning, 39(3), 313-338.

Boud, D., \& Molloy, E. (2013). Rethinking models of feedback for learning: the challenge of design. Assessment and Evaluation in Higher Education, 38(6), 698-712

Butler, Y. G., \& Lee, J. (2010). The effects of self-assessment among young learners of English. Language Testing, 27(1), 5-31. 
Carless, D. (2007). Learning oriented assessment: conceptual bases and practical implications. Innovations in Education and Teaching International, 44(1), 57-66.

Coverdale-Jones, T. (2000). The use of video-conferencing as a communication tool for language learning: issues and considerations. IALL Journal, 32(1), 27-40.

De Los Arcos, B., Coleman, J. A., \& Hampel, R. (2009). Learners' anxiety in audiographic conferences: a discursive psychology approach to emotion talk. ReCALL, 21(1), 3-17.

Devellis, R. (2001). Scale development: theory and applications: theory and application. Thousand Okas: Sage.

Dörnyei, Z. (2005). The psychology of the language learner: Individual differences in second language acquisition. Mahwah: Lawrence Erlbaum.

Ellis, R. (2006). Researching the effects of form-focussed instruction on L2 acquisition. AllA Review, 19, 18-41.

Ertmer, P. A., Richardson, J. C., Belland, B., Camin, D., Connolly, P., Coulthard, G., Lei, K., \& Mong, C. (2007). Using peer feedback to enhance the quality of student online postings: An exploratory study. Journal of Computer-Mediated Communication, 12, 78-99.

Fukuda, Y. (2004). Treatment of spoken errors in Japanese high school oral communication classes. Master's thesis. San Francisco: California State University.

Gielen, S., Tops, L., Dochy, F., Onhema, P., \& Smeets, S. (2010). A comparative study of peer and teacher feedback and of various peer feedback forms in a secondary writing curriculum. British Educational Research Journal, 36, 143-162.

Hassan, J.A., Das, S.K., Hassan, M., Bisdikian, C., \& Soldani, D. (2005). Improving quality of experience for network services. EEE Network: The Magazine of Global Internetworking - Special issue on improving quality of experience for network services, 24(2), 4-6, March/April 2010.

Herrington, R. O., \& Reeves, T. C. (2003). Patterns of engagement in authentic online learning environments. Australian Journal of Educational Technology, 19(1), 59-71.

Hopkins, J. (2010). Distance language learners' perceptions of assessed, student-led speaking tasks via a synchronous audiographic conferencing tool. Innovation in Language Learning and Teaching, 4(3), 235-258.

Horwtiz, E. K., Horwitz, M. B., \& Cope, J. (1986). Foreign language classroom anxiety. Modern Language Journal, 70, 125-132.

Huang, H. M. (2002a). Toward constructivism for adult learners in online learning environments. British Journal of Educational Technology, 33(1), 27-37.

Huang, H. M. (2002b). Student perceptions in an online mediated environment. International Journal of Instructional Media, 29(4), 405-422.

Ion, G., Silva, P., \& Cano, E. (2013). El feedback y el feedforward y la evaluación de las competencias de los estudiantes universitarios. Profesorado. [Feedback and feedforward in the assessment of students' competences in higher education]. Revista de currículum y formación del profesorado, 17(2), 283-301.

Jonassen, D. H. (1994). Thinking technology: toward a constructivist design model. Educational Technology, 34(4), 34-37.

Kavalauskiene, G., \& Anusiene, L. (2012). Case study: learner attitudes towards the correction of mistakes. Social Technologies, 2(1), 88-101.

Koohang, A. (2009). A learner-centered model for blended learning design. International Journal of Innovation and Learning, 6(1), 76-91.

Koohang, A., Riley, L., Smith, T., \& Schreurs, J. (2009). E-learning and constructivism: from Theory to Application. Interdisciplinary Journal of E-Learning and Learning Objects, 5, 91-109.

Krashen, S. (1982). Principles and practice in second language acquisition. Oxford: Pergamon.

Lee, E. J. (2016). Reducing international graduate students' language anxiety through oral pronunciation corrections. System, 56, 78-95.

Lin, H. (2015). A meta-synthesis of empirical researchon the effectiveness of computer-mediated communication (CMC) in SLA. Language, Learning and Technology, 19(2), 85-117.

Lochtman, K. (2002). Oral corrective feedback in the foreign language classroom: how it affects interaction in analytic foreign language teaching. International Journal of Educational Research, 37, 271-283.

Lyster, R., \& Ranta, L. (1997). Corrective Feedback and Learner Uptake. SSLA, 20, 30-71.

Martínez, J. (2013). An investigation into how EFL learners emotionally respond to teachers' oral corrective feedback. Colombian Applied Linguistics Journal, 15(2), 265-278.

McNeil, L. (2014). Ecological affordance and anxiety in an oral asynchronous computer-mediated environment. Language Learning \& Technology, 18(1), 142-159. Retrieved from http://lt.msu.edu/issues/february2014/mcneil.pdf

Murphy, E. (1997). Constructivism: from philosophy to practice (Technical Report) Retrieved from https://eric.ed.gov/?id=ED444966

Ozmen, K. S., \& Aydın, H. Ü. (2015). Examining student teachers' beliefs about oral corrective feedback: insights from a teacher education program in Turkey. Australian Journal of Teacher Education, 40(12), 141-164. Retrieved from http://dx.doi.org/10.14221/ajte.2015v40n12.10

Renko, K. (2012). Finnish EFL Learners' perceptions on errors, corrective feedback and foreign language anxiety. Master's Thesis. Retrieved from http://urn.fi/URN:NBN:fi:jyu-201210122672

Rollinson, P. (2005). Using peer-feedback in the ESL writing class. ELT Journal, 59(1), 23-30.

Roseberry, S., Hirsh-Pasek, K., \& Golinkoff, R. M. (2014). Skype Me! Socially Contingent Interactions Help Toddlers Learn Language. Child Development, 85(3), 956-970.

Ross, S. (1998). Self-assessment in second language testing: a meta-analysis and analysis of experiential factors. Language Testing January, 15(1), 1-20.

Sheen, Y. (2008). Recasts, language anxiety, modified output, and L2 learning. Language Learning, 58(4), 835-874.

Shute, V. J. (2007). Focus on formative feedback. Research Report. Princeton: Educational Testing Service.

Steppe-Greany, J. (2002). Student perceptions on language learning in a technological environment: implications for the new millenium. Language, Learning and Technology, 6(1), 165-180.

Surakka, K. (2007). Corrective feedback and learner uptake in an EFL classroom. Finland: Published master thesis, University of Jyväskylä.

Tavangarian, D., Leypold, M., Nölting, K., Röser, M., \& Voigt, D. (2004). Is e-Learning the Solution for Individual Learning? Journal of e-Learning, 2(2), 273-280.

Tseng, S., \& Tsai, C. C. (2007). On-line peer assessment and the role of the peer feedback: A study of high school computer course. Computers and Education, 49, 1161-1174. 
Van den Boom, G., Paas, F., \& Van Merriënboer, J. (2007). Effects of elicited reflections combined with tutor or peer feedback on self-regulated learning and learning outcomes. Learning and Instruction, 17, 532-548.

Ward, R., Moule, P., \& Lockyer, L. (2009). Adoption of Web 2.0 technologies in education for health professionals in the UK: where are we and why? Electronic Journal of e-Learning, 7(2), 165-172.

Yu, W., She, H., \& Lee, Y. (2010). The effects of web-based/non-web-based problemsolving instruction and high/low achievement on students' problem-solving ability and biology achievement. Innovations in Education and Teaching International, 47(2), 187-199.

Zhang, L. J., \& Rahimi, M. (2014). EFL learner's anxiety level and their beliefs about corrective feedback in oral communication classes. System, 42, 429-4.

Zhanming, W. (2014). Review of the Influence of L1 in L2 Acquisition. Studies in Literature and Language, 9(2), 57-60.

Zheng, Y. (2008). Anxiety and second/foreign language learning revisited. Canadian Journal for New Scholars in Education, 1(1). Retrieved from https://journalhosting.ucalgary.ca/index.php/cjnse/article/view/30393/24835

Submit your manuscript to a SpringerOpen ${ }^{\odot}$ journal and benefit from:

- Convenient online submission

- Rigorous peer review

- Immediate publication on acceptance

- Open access: articles freely available online

- High visibility within the field

- Retaining the copyright to your article

Submit your next manuscript at $>$ springeropen.com 